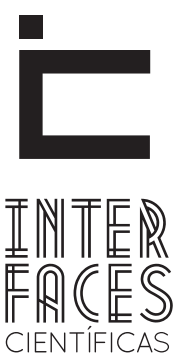

EDUCAÇÃO

ISSN IMPRESSO 2316-333X

ISSN ELETRÔNICO 2316-3828

Dossiê

\title{
O LIVRO DIDÁTICO E A CIRCULAÇÃO DO CONHECIMENTO: UMA ANÁLISE DA QUESTÃo AMBIENTAL NA GEOGRAFIA ESCOLAR
}

Márcia Eliane Silva Carvalho ${ }^{1}$ Liliane de Jesus Dias ${ }^{3}$
Jussara Nascimento Cunha ${ }^{2}$

Lucas Lima ${ }^{4}$

Vanilza da Costa Andrade ${ }^{5}$

\section{RESUMO}

A circulação do conhecimento tem como um dos espaços formais de ocorrência a instituição escolar. Nestes espaços, o livro didático tem sido tomado como um grande aliado dos docentes e discentes, pois nele estão sistematizados os saberes historicamente acumulados pela ciência. Nessa perspectiva, o presente artigo tem por objetivo analisar como circula o conhecimento acerca da temática ambiental em livros didáticos de geografia do ensino fundamental, antigas $5^{\mathrm{a}}$ a $8^{\mathrm{a}}$ séries. Para atingir os objetivos propostos esta pesquisa foi baseada na abordagem qualitativa, sendo dividida em dois momentos: levantamentos bibliográficos e analisadas de duas coleções didáticas.
Na coleção Geografia, Homem e Espaço as questões ambientais predominam nos de textos complementares. $\mathrm{Na}$ coleção Geografia, Sociedade e Cotidiano a questão ambiental é tratada em capítulos específicos, ou seja, os autores discutem e sugerem medidas para preservação/conservação dos recursos naturais. De modo geral, a questão ambiental nos livros analisados, instiga os professores e alunos para discussão dos problemas locais, através de textos e atividades complementares. Mas recai sobre o docente permitir esta leitura. Sendo assim, as duas coleções analisadas apresentam a temática de forma a possibilitar a circulação do conhecimento sobre a temática 
ambiental, mas para isso é necessário o engajamento e comprometimento do professor para desenvolver discussões e projetos que retratem os problemas ambientais da atualidade.

\section{ABSTRACT}

The circulation of knowledge is one of the formal spaces of occurrence school institution. In these spaces, the textbook has been taken as a major ally of the teachers and students because it is historically systematized the knowledge accumulated by science. In this perspective, this article aims to analyze how knowledge circulates about environmental issues in geography textbooks of elementary school, old 5 th to 8 th grades. To achieve the proposed objectives this research was based on a qualitative approach, which is divided into two stages: literature surveys and analyzed two textbook collections. In Geography, Man and Space Collection environmental issues predominate in the supplementary texts. In Geography, Society and Everyday Collection environmental issue is addressed in specific chapters, ie, the authors discuss and suggest measures for preservation / conservation of natural resources. In general, the environmental issue in the books analyzed, instigates teachers and students for discussion of local issues, through texts and supplementary activities. But lies with the teacher allow this reading. Thus, the two collections have analyzed the topic in order to allow the circulation of knowledge about environmental issues, but usually the engagement and commitment of the teacher to develop discussions and projects that portray the environmental problems is necessary.

\section{KEYWORDS}

Movement of Knowledge. Textbook. Environmental Theme. Teaching Geography.

\section{PALAVRAS-CHAVE}

Circulação do conhecimento. Livro Didático. Temática Ambiental. Ensino de Geografia

\section{RESUMEN}

La circulación del conocimiento es uno de los espacios formales de la institución escolar ocurrencia. En estos espacios, el libro de texto se ha tomado como un importante aliado de los profesores y los estudiantes, ya que está históricamente sistematizó el conocimiento acumulado por la ciencia. En esta perspectiva, este artículo tiene como objetivo analizar cómo el conocimiento circula por las cuestiones ambientales en los manuales de geografía de la escuela primaria, edad 5 al $8^{\circ}$ grado. Para lograr los objetivos propuestos esta investigación se basa en un enfoque cualitativo, que se divide en dos etapas: encuestas literatura y analizó dos colecciones de libros de texto. En Geografía, medio ambiente del hombre y de la colección Espacio predominan en los textos complementarios. En Geografía, tema ambiental Sociedad y todos los días se aborda en los capítulos específicos, es decir, los autores discuten y proponen medidas para la preservación / conservación de los recursos naturales. En general, el tema del medio ambiente en los libros analizados, instiga a los profesores y estudiantes para la discusión de los problemas locales, a través de los textos y las actividades complementarias. Pero corresponde a los profesores permiten a esta lectura. Por lo tanto, las dos colecciones han analizado el tema con el fin de permitir la circulación de los conocimientos acerca de los problemas ambientales, pero por lo general la participación y el compromiso del maestro para desarrollar discusiones y proyectos que retratan los problemas ambientales es necesario.

\section{PALABRAS CLAVE}

Movimiento de conocimiento. Libro de Texto. Tema Ambiental. Enseñanza Geografía. 


\section{INTRODUÇÃ̃O}

A circulação do conhecimento tem como um dos espaços formais de ocorrência a instituição escolar. Estas instituições, sejam elas voltadas para o ensino fundamental ou médio, caracterizam-se legalmente como o lócus da produção, circulação, transmissão e assimilação do conhecimento, não negando a existência e a importância de outros espaços educativos.

Nestes espaços, o livro didático tem sido tomado como um grande aliado dos docentes e discentes, pois nele estão sistematizados os saberes historicamente acumulados pela ciência.

O livro didático, além de reunir estes saberes deve contemplar temas de relevância social e atual para permitir aos seus leitores um conhecimento atualizado e necessário a uma formação cidadã.

Dentre estes temas, a problemática ambiental tem destaque e ganhou escopo principalmente depois dos grandes desastres causados pela exploração não racional dos bens naturais.

Segundo Mendonça (1998), a discussão ambiental ganha importância na atualidade devido principalmente a três fatores tais como: o caos da qualidade de vida da população, o alarmismo da mídia que expõe os fenômenos naturais sob a noção de acidente, catástrofe, etc, e o papel das ciências, das artes e da atividade política que cada vez mais estão mostrando em seus trabalhos os fenômenos ambientais, dando enfoque as catástrofes e "vingança" da natureza.

Os Parâmetros Curriculares Nacionais (BRASIL, 1997) compreendem o meio ambiente como um tema transversal que deve permear os currículos escolares, possibilitando uma postura crítica frente as questões ambientais.

Tais conteúdos devem conter uma visão integradora da realidade do ponto de vista socioambiental e po- lítico (tema este nem sempre trabalhado), buscando sensibilizar para mudanças de valores e atitudes para o exercício pleno da cidadania.

Nestes termos, a ciência geográfica destaca-se, pois historicamente tem como objeto de estudo a sociedade e a natureza de forma integrada, sendo próprio desta ciência desvendar as relações entre o homem e o meio.

Materializando estas reflexões, o livro didático emerge como elo de produção do conhecimento produzido na academia e a sociedade. Mas ele tem abarcado estes pressupostos supracitados?

Nessa perspectiva, o presente artigo tem por objetivo analisar como circula o conhecimento acerca da temática ambiental em livros didáticos de geografia do ensino fundamental, antigas $5^{a}$ a $8^{a}$ séries (nomenclatura que será mantida, pois para o período em análise não havia ocorrido a mudança do ciclo escolar para nove anos) no período compreendido entre os anos de 2004 a 2006.

Vale destacar que na realidade da maioria das escolas públicas, o livro didático é uma das fontes mais importantes tanto para docentes quanto para discentes, auxiliando ambos no processo de ensino-aprendizagem, embora não deva ser a única, pois outras formas de circulação do conhecimento devem contribuir para efetivar este processo, além de estreitar os laços entre alunos e escola.

Para atingir os objetivos propostos esta pesquisa foi baseada na abordagem qualitativa, sendo dividida em dois momentos: em um primeiro momento foram realizados levantamentos bibliográficos acerca da temática, utilizando-se os seguintes autores: Brandão, 1995; Brasil, 1997; Guimarães, 2005; Leonardi, 1999; Loureiro, 2006; Mendonça, 1998; Penteado, 2000; Reigota, 1998 e Troppmair, 2006. 
Em um segundo momento foram selecionadas e analisadas duas coleções - Geografia Homem e Espaço (LUCCI e BRANCO, 2004) e Geografia Sociedade e Cotidiano (BIGOTTO, VITIELLO e ALBUQUERQUE, 2006), cujos questionamentos considerados para análise foram: Como circula o conhecimento sobre a questão ambiental nos livros didáticos selecionados? De que forma isto acontece? Através do uso dos referidos livros, há a formação de uma leitura crítica ambiental no ensino de Geografia?

\section{A CIRCULAÇ̃̃O DO CONHECIMENTO SOBRE A QUESTÃO AMBIENTAL EM LIVROS DIDÁTICOS DE GEOGRAFIA}

De acordo com Penteado (2000, p. 54), o espaço escolar se caracteriza como uma possibilidade de desenvolvimento de uma leitura ambiental não meramente biológica, mas que considere as dimensões sociais e políticas.

O desenvolvimento da cidadania e a formação da consciência ambiental têm na escola um local adequado para sua realização através de um ensino ativo e participativo, capaz de superar os impasses e insatisfações vividas de modo geral pela escola na atualidade, calcado em modos tradicionais.

A circulação do conhecimento tem importante papel na formação cidadã, pois permite ao educando estar em contato com a produção do conhecimento pretérito e presente. No entanto, emerge uma indagação: Como este conhecimento está circulando? Especificamente no ensino de Geografia, como a temática ambiental tem sido abordada?

Na coleção Geografia Homem e Espaço (LUCCl e BRANCO, 2004) a questão ambiental é abordada em textos complementares, sendo que os autores mostram algumas preocupações em discutir essa temática. No livro da $5^{a}$ série, cuja temática central é "A natureza, o homem, e a organização do espaço", a temática é discutida mais profundamente em textos complementares, devido ao conteúdo que é voltado para as questões naturais do planeta.
Nesta série são propostas atividades que sugerem que o aluno pense e questione sua própria ação/postura sobre o meio ambiente, tomemos como exemplo uma atividade sobre a consciência ambiental do aluno. 0 livro traz textos no final de capítulos com questões nesta perspectiva de conscientizar o aluno sobre o meio ambiente, com uso de ilustrações, com quadros indagando quanto o homem consome água em determinadas atividades (escovar os dentes, lavar o rosto, tomar banho etc.).

Vale ressaltar que no período em análise 2004 a 2006 ainda perdurava a ideia de conscientizar. Atualmente, este termo demonstra ser inadequado, pois não mudamos mentes, pode-se sensibilizar os cidadão para mudança de valores, na busca de ações que minimizem a degradação que a sociedade como um todo exerce sobre o ambiente.

No capítulo A atividade Industrial e as Fontes de Energia, observa-se a ênfase nas consequências do consumo acirrado com a produção de lixo, possibilitando a circulação da informação relativa a necessidade de redução do consumo. 0 livro especificamente valoriza a politica dos 'três erres'- reduzir, reutilizar e reciclar.

No livro da $6^{\mathrm{a}}$ série dos referidos autores, cuja temática central é "A organização do espaço brasileiro", praticamente todos os capítulos enfocam questões re- 
lacionadas ao meio ambiente, especialmente no que versa sobre a paisagem natural brasileira e a ação humana. São textos complementares de como o homem interfere na paisagem natural. Dentre alguns textos complementares que abordam a temática vale destacar: Processo de desertificação do semiárido (capítulo O Nordeste); a biopirataria (capítulo A Amazônia); A agricultura tropical adequada a Amazônia (capítulo 0 espaço socioeconômico da Amazônia); Agrotóxicos e sua consequência para a saúde humana (capítulo sobre o espaço agrário do Brasil).

Para a $7^{a}$ série desta mesma coleção, cujo eixo principal é “O capitalismo, as condições de desenvolvimento, os blocos econômicos e o espaço americano", o tema carece de um maior aprofundamento, pois apenas dois capítulos trabalham a questão ambiental, sendo que a discussão desses problemas está destacada em apenas dois textos complementares. No capítulo 0 relevo e a hidrografia do continente americano a questão ambiental é trabalhada no texto "Reservatório modificou o ecossistema da região" e no capítulo $\mathrm{O}$ clima e as paisagens vegetais da América a temática é abordada no texto "Caatinga: agroecologia versus desertificação".

Compreende-se que nesta série, considerando a temática Capitalismo, a questão ambiental deveria ser mais amplamente discutida, pois o acirramento da degradação ambiental e de qualidade de vida de grande parcela da população mundial ocorreu após o crescimento sem limites deste modo de produção. Sendo assim, o professor como agente transmissor de conhecimento deve buscar outras formas de circular o conhecimento sobre este tema, promovendo debates através de outros veículos informativos.

No livro da $8^{a}$ série dos mesmos autores, cujo tema principal "As relações internacionais e a organização do espaço mundial”, a questão ambiental também é enfocada em textos complementares e sob o aspecto de catástrofes ambientais. 0 recorte socioambiental, as mazelas sociais não estão agregadas ao tema. Então cabe ao educador promover outras leituras e ana- lises junto aos alunos, procurando de início analisar as questões ambientais em âmbito local para em seguida preocupar-se com os problemas globais.

Nesta coleção, predomina o uso de textos complementares para abordar a temática em tela. Isto é interessante, pois além de abordar os conteúdos tidos como obrigatórios para o ensino de geografia nas referidas séries analisadas, permite o desenvolvimento da leitura e análise critica do tema, desde que o docente possibilite esta análise, ou seja, também recai sobre o docente a responsabilidade de permitir estas análises e ir além do conteúdo básico, permitindo a ampliação da circulação do conhecimento.

A segunda coleção analisada - Geografia Sociedade e Cotidiano, (BIGOTTO, VITIELLO e ALBUQUERQUE, 2006) a temática ambiental é trabalhada na maioria dos seus capítulos, ou seja, quando não vêm em tópicos específicos, a questão ambiental é mostrada em atividades e/ou textos complementares. Com essas sugestões de textos, os professores junto com os alunos poderão fazer discussões e completar com a realidade e conhecimento dos discentes sobre as questões ambientais.

Nesta coleção, o livro da $5^{a}$ série cuja temática geral - "Fundamentos do espaço geográfico", o tema ambiente é abordado de forma transversal. No capítulo da camada da terra - hidrosfera há uma valorização da conscientização de preservar a água colocando sua importância no desenvolvimento das atividades humanas e assim a necessidade de sua conservação. São apresentados também subtópicos sobre a poluição da água e os impactos ambientais ocasionados pela própria sociedade.

Assim, o capítulo traz textos com letra de músicas e relatos de populações sobre a importância da água para eles e as atividades propostas, fazendo o aluno pensar sobre a questão da água a partir da realidade local, ora sobre a importância da água para a existência de identidade de certos grupos sociais e também 
para toda humanidade, ora enfatiza como o ser individual pode contribuir na vida doméstica para economizar a água, assim como a responsabilidade de toda a sociedade para uma relação harmônica entre homem e meio ambiente.

No livro da $6^{\mathrm{a}}$ série dos referidos autores, cujo tema geral é "Espaço brasileiro", há uma maior ênfase para as questões ambientais, retratando os problemas ambientas na atualidade. No capítulo Domínios Naturais do Brasil são discutidos aspectos referentes aos impactos ambientais, questões como degradação, desmatamento, desertificação, construção de usinas hidrelétricas, perda da biodiversidade, mudanças climáticas são explanados, isso mostra o interesse e a preocupação dos autores em discutir os problemas que afeta os seres vivos e o próprio homem com a destruição do meio natural.

No capítulo Meio Urbano: Características Sociais e Ambientais, todo o seu conteúdo é voltado para discussão das questões ambientais, isto é, os autores mostram quais problemas o homem está sujeito a enfrentar/conviver no meio urbano. Fazendo abordagens sobre poluição do ar, escassez das águas, áreas verdes, os autores além de discutir esses problemas pelo qual o ambiente está passando, os mesmos mostram algumas sugestões para preservação do meio natural. Dessa forma, os autores trazem reflexos sobre as questões ambientais, cabe ao professor dialogar com os alunos sobre esses processos de destruição/modificação da natureza, e a partir da conscientização e participação da sociedade civil discutir sobre os problemas socioambientais que afetam toda a biodiversidade, incluindo o homem.

No livro da $7^{a}$ série, da mesma coleção, cuja temática central é "Espaço mundial I" apenas no capítulo "Os domínios naturais do espaço geográfico mundial”, a temática é tratada em duas atividades complementares: “Ambientes ameaçados” e "Utilização racional dos recursos naturais". Diante disso, percebemos que esse livro poderia aprofundar mais sobre os grandes proble- mas ambientais que repercutem no mundo como um todo. Porém os professores junto com os alunos podem dialogar e buscar novas propostas que complementem as que são trabalhadas no livro didático.

No livro da $8^{a}$ série da mesma coleção, cujo tema principal é “Espaço mundial II” a temática ambiental é abordada em um capítulo específico acerca de questões socioambientais do mundo, apresentando os principais problemas ambientais da atualidade (desmatamento, poluição do ar, mudanças climáticas, efeito estufa, poluição da água e escassez hídrica), as correntes ambientalistas e as conferências internacionais sobre o meio ambiente. Essa coleção em especial pode orientar o docente no processo de ensino-aprendizagem, pois ela coloca em questão as problemáticas ambientais, focalizando as conferências internacionais das Nações Unidas para o Meio Ambiente, permitindo assim que o discente compreenda que o pensar sobre o ambiente não é modismo, ao mesmo tempo em que busca o despertar para a conscientização ambiental e para a busca de uma maior atuação política frente aos interesses econômicos e aos atos consumistas e imediatistas da sociedade capitalista atual.

Dessa forma, é a partir da circulação da informação através dos conteúdos do livro didático e do convívio escolar que os discentes irão criar uma reflexão para o necessário reconhecimento da importância de ter o tema ambiental no cerce na discussão do processo educativo.

A conservação ambiental e não apenas a preservação do meio natural se faz necessária no meio educativo, conforme ressalta Reigota (1998, p. 28), “o desafio da educação ambiental é sair da ingenuidade e do conservadorismo (biológico e político) a que se viu confinada e propor alternativas sociais, considerando a complexidade das relações humanas e ambientais".

Trabalhar com a temática ora proposta subtendese também ter um olhar especifico para a formação voltada para a educação ambiental. Mudança de va- 
lores e ações são elementos que necessitam ter sua semente plantada na educação básica. Medidas imediatas são necessárias, mas somente uma formação consciente e cidadã mudará o cenário futuro da Terra. Para tal, a circulação a informação e um olhar para a formação socioambiental proporcionada pelo ensino de Geografia pode contribuir para grandes mudanças.

Mesmo tendo analisado apenas duas coleções didáticas, foi possível identificar como a ciência geográfica traz em seu bojo as interações entre sociedade e natureza. Mesmo tendo um olhar especial para as relações socioambientais, a educação ambiental também permeia as relações estabelecidas no contexto escolar.

A educação ambiental, antes de tudo, é educação. Mas não uma educação genérica, e sim aquela que se nutre das pedagogias progressistas histórico-crítico e liber-

\begin{abstract}
tária, que são as correntes orientadas para a transformação social. Por isso "é absolutamente crucial para a concretização de um novo patamar societário que a produção em Educação Ambiental aprofunde o debate teórico-prático acerca daquilo que pode tornar possível ao educador discernir uma concepção ambientalista e educacional conservadora e tradicional de uma emancipatória e transformadora, e as variações e nuances que aí se inscrevem" (LOUREIRO, 2006, p.15).
\end{abstract}

Estas análises foram realizadas em coleções datadas de 2004 e 2006. No entanto, pouco se observa em termos de mudanças na realidade socioambiental em que vivemos. As referidas coleções ainda circulam no cenário educativo, com novas edições, revisão de textos e imagens, mas com a mesma essência. Mesmo finalizando a análise, ainda resta uma grande questão para ser ampliada. 0 que ainda necessita ser feito no tocante a uma (re)orientação das relações ambiente/ sociedade além da circulação do conhecimento?

\section{CONSIDERACÕ̃ES FINAIS}

No marco das questões ambientais atuais é preciso que o homem se insira como participante na busca de uma relação harmônica entre sociedade/natureza. Diante disso, a circulação do conhecimento nos livros didáticos demonstra a importância do mesmo na formação do cidadão. Ao mesmo tempo demonstra o papel fundamental que o docente deve dedicar na seleção do livro didático a ser adotado na escola.

A temática ambiental expressas nos livros didáticos analisados datados de 2004 e 2006 buscou, com algumas exceções por série, contribuir para formação do homem em quanto ser social, engajado com as questões ambientais e imprimindo uma postura responsável em relação ao meio, principalmente de sua realidade local. Sobre isso Leonardi, (1999, p. 406) afirma que “(...) a educação ambiental não pode, por si só, respon- der aos graves desafios, inclusive até de sobrevivência física de amplas camadas da população mundial." Mas deve despertar o repensar de ações e valores.

Um ponto frágil no que tange a temática em debate é a ausência da discussão acerca do papel político frente às questões ambientais, bem como da determinação do poder econômico que faz prevalecer interesses capitalistas frente ao uso mais equânime dos recursos naturais.

Este é um ponto nem sempre abordado, mas cabe ao docente instigar seus alunos a refletirem sobre tal, pois não basta existirem políticas públicas e um discurso político de preservação ambiental, se os mesmos não saem do papel e se cada vez mais o ambiente é explorado para sustentar a 
riqueza de uma minoria, enquanto a maioria carece de condições dignas de vida. A qualidade ambiental perpassa também pela social.

Nas coleções analisadas verifica-se que a temática ambiental é enfocada principalmente em textos complementares, porém nos livros da $6^{\mathrm{a}}$ e $8^{\mathrm{a}}$ séries da coleção Sociedade e Cotidiano a questão ambiental é tratada em capítulos específicos, ou seja, os autores discutem e sugerem medidas para preservação/ conservação dos recursos naturais. De modo geral, a questão ambiental nos livros analisados, instiga os professores e alunos para discussão dos problemas locais, através de textos e atividades complementares.

Embora os autores discutam as questões ambientais na maioria dos livros didáticos analisados, os livros da $7^{a}$ série em especial não trazem uma abordagem específica para educação ambiental, isso devido à própria temática que é voltada para as questões capitalistas e suas contradições. Porém, é nessa série que os autores deveriam discuti-la com maior ênfase, pois com sistema capitalista de produção, os recursos naturais são explorados de forma exacerbada, isso devido ao consumismo e a necessidade imediata de lucro.

Sendo assim, as duas coleções analisadas apresentam a temática de forma a possibilitar a circulação do conhecimento sobre a temática ambiental, mas para isso é necessário o engajamento e comprometimento do professor para desenvolver discussões e projetos que retratem os problemas ambientais da atualidade.

\section{REFERÊNCIAS}

BIGOTTO, José Francisco, VITIELLO, Márcio Abondanza; ALBUQUERQUE, Maria Adailza Martins de. Geografia: Sociedade e Cotidiano: fundamentos do espaço geográfico. $5^{a}$ série. 1. ed. São Paulo: Escala Educacional, 2006.

BIGOTTO, José Francisco, VITIELLO, Márcio Abondanza; ALBUQUERQUE, Maria Adailza Martins de. Geografia: Sociedade e Cotidiano: espaço brasileiro. $6^{\mathrm{a}}$ série. 1. ed. São Paulo: Escala Educacional, 2006.

BIGOTTO, José Francisco, VITIELLO, Márcio Abondanza; ALBUQUERQUE, Maria Adailza Martins de. Geografia: Sociedade e Cotidiano: espaço mundial I. $7^{\text {a }}$ série. 1. ed. São Paulo: Escala Educacional, 2006.

BIGOTTO, José Francisco, VITIELLO, Márcio Abondanza; ALBUQUERQUE, Maria Adailza Martins de. Geografia: Sociedade e Cotidiano: espaço mundial II. $8^{\mathrm{a}}$ série. 1. ed. São Paulo: Escala Educacional, 2006.
BRASIL. Secretaria de Educação Fundamental. Parâmetros curriculares nacionais: Meio Ambiente, Saúde. Brasília: MEC/SEF, 1997.

BRANDÃO, Carlos Rodrigues. 0 que é educação. 33. ed. São Paulo: Brasiliense, 1995.

\section{GUIMARÃES, Mauro. Sustentabilidade e Educação}

Ambiental. In: CUNHA, Sandra Baptista da; GUERRA, Antonio José Teixeira. (orgs). A Questão Ambiental: Diferentes Abordagens. 2. ed. Rio de Janeiro: Bertrand Brasil, 2005, p. 81-105.

LEONARDI, Maria Lúcia Azevedo. A Educação Ambiental como um dos instrumentos de superação da insustentabilidade da sociedade atual. In: CAVALCANTI, Clóvis (org). Meio Ambiente, Desenvolvimento Sustentável e Políticas Públicas. 2. ed. São Paulo: Cortez, 1999. 
LOUREIRO, Carlos Frederico B. Trajetórias e Fundamentos da Educação Ambiental. 2. ed. São Paulo: Cortez, 2006.

LUCCI, Elian Alabi; BRANCO, Anselmo Lazaro. Geografia: Homem e Espaço - a natureza, o homem, e a organização do espaço. $5^{a}$ série: Ensino Fundamental. 18. ed. São Paulo: Saraiva, 2004.

LUCCI, Elian Alabi; BRANCO, Anselmo Lazaro. Geografia: Homem e Espaço - a organização do espaço brasileiro. $6^{\mathrm{a}}$ série: Ensino Fundamental. 19. ed. São Paulo: Saraiva, 2004.

LUCCI, Elian Alabi; BRANCO, Anselmo Lazaro. Geografia: Homem e Espaço - o capitalismo, as condições de desenvolvimento, os blocos econômicos e o espaço americano. $7^{a}$ série: Ensino Fundamental. 19. ed. São Paulo: Saraiva, 2004.
LUCCI, Elian Alabi; BRANCO, Anselmo Lazaro. Geografia: Homem e Espaço - as relações internacionais e a organização do espaço mundial. $8^{a}$ série: Ensino Fundamental. 19. ed. São Paulo: Saraiva, 2004.

MENDONÇA, Francisco de Assis. Geografia e Meio Ambiente. 3. ed. São Paulo: Contexto, 1998.

PENTEADO, Heloísa Dupas. Meio ambiente e formação de professores. 3. ed. São Paulo: Cortez, 2000.

REIGOTA, Marcos. Meio Ambiente e Representação Social. 3. ed. São Paulo: Cortez, 1998.

TROPPMAIR, Helmut. Biogeografia e Meio Ambiente. 7. ed. Rio Claro: Divisa, 2006.

1 Professora do Departamento de Geografia/UFS. Doutora em Geografia/ NPGEO/UFS; Mestre em Geografia/NPGEO/UFS; Pesquisadora dos Grupos de Pesquisa: GEOPLAN E GEPEASE. E-mail: marciacarvalho@ufs.br

2 Licenciada em Geografia/UFS. E-mail: jussara_geo@yahoo.com.br

3 Licenciada em Geografia/UFS. E-mail: tilianejdias@hotmail.com

4 Licenciado em Geografia/UFS. E-mail: lucaslimajb@hotmail.com

5 Licenciada em Geografia/UFS. Mestre em Geografia/NPGEO/UFS E-mail: vanilza_geo@hotmail.com 